\title{
Assessment of factual measurement times for chlorophyll- $a$ fluorescence in rubber (Hevea brasiliensis) clones
}

\author{
ANDI NUR CAHYO ${ }^{1,2, \bullet}$, RUDI HARI MURTI ${ }^{2}$, EKA T.S. PUTRA ${ }^{2}$, TRI RINI NURINGTYAS ${ }^{3,4}$, DENIS FABRE, \\ PASCAL MONTORO ${ }^{5,6}$ \\ ${ }^{1}$ Indonesian Rubber Research Institute, Jl. Palembang-Pangkalan Balai km. 29, Sembawa, Banyuasin 30953, South Sumatra, Indonesia. \\ Tel.: +62-711-7439493, Fax.: +62-711-7439282, "email: nurcahyo.andi@yahoo.co.uk \\ ${ }^{2}$ Faculty of Agriculture, Universitas Gadjah Mada. Jl. Flora, Bulaksumur, Sleman 55281, Yogyakarta, Indonesia \\ ${ }^{3}$ Faculty of Biology, Universitas Gadjah Mada. Jl. Teknika Selatan, Sekip Utara, Sleman 55281, Yogyakarta, Indonesia \\ ${ }^{4}$ Research Centre for Biotechnology, Universitas Gadjah Mada. Jl. Teknika Utara, Sleman 55281, Yogyakarta, Indonesia \\ ${ }^{5}$ CIRAD, UMR AGAP Institut. F-34398 Montpellier, France \\ ${ }^{6}$ UMR AGAP Institut, Univ Montpellier, CIRAD, INRAE, Institut Agro. F-34398 Montpellier, France
}

Manuscript received: 20 March 2021. Revision accepted: 29 May 2021.

\begin{abstract}
Cahyo AN, Murti RH, Putra ETS, Nuringtyas TR, Fabre D, Montoro P. 2021. Assessment of factual measurement times for chlorophyll-a fluorescence in rubber (Hevea brasiliensis) clones. Biodiversitas 22: 3470-3477. Chlorophyll- $a$ fluorescence is widely used to determine the stress tolerance levels of some plant species. Measurement of chlorophyll- $a$ fluorescence is accurate if the duration of dark adaptation is well defined and optimal $\mathrm{F}_{\mathrm{v}} / \mathrm{F}_{\mathrm{m}}$ (maximum quantum yield of primary photochemistry/photosynthesis) is achieved. Leaf clips are usually used to darken the leaf prior to measurement. This procedure takes time and limits the use of chlorophyll- $a$ fluorescence parameter in high-throughput screening of genetic populations. This study aimed to determine the most suitable time for the chlorophyll-a fluorescence measurement. This study was carried out on several rubbers (Hevea brasiliensis Müll. Arg.) clones and consisted of two steps. The first step was conducting the measurements at five different times at night: at 7.30, 8.00, 8.30, 9.00, and 9.30 p.m. The second step was conducting the measurements at daytime, which consisted of two factors. The first factor was the measurement time, which was divided into two categories: 7.30 a.m. and 1.30 p.m. The second factor was the duration of dark adaptation using leaf clips, which consisted of nine levels: 0, 15, 30, 45, 60, 75, 90, 105, and 120 min. Additional treatment (measurement at 9.00 p.m. without using leaf clips to darken the leaf) was used as a control. This study revealed that a dark adaptation time of two hours after the sunset was long enough for the rubber leaves chlorophyll- $a$ fluorescence transient to be measured without using leaf clips for the dark adaptation. If the measurement is conducted by 7.30 a.m., the clone RRIM 600, GT1, and SP 217 required 15 min of dark adaptation, whereas clone PB 260 required 60 min of dark adaptation. Furthermore, measurement of chlorophyll- $a$ fluorescence in the afternoon is not recommended due to the potentially high microclimate fluctuation.
\end{abstract}

Keywords: Chlorophyll- $a$ fluorescence, dark adaptation, $\mathrm{F}_{\mathrm{v}} / \mathrm{F}_{\mathrm{m}}$, Hevea brasiliensis, performance index

Abbreviations: a.u.: arbitrary unit; CF: chlorophyll- $a$ fluorescence; DMRT: Duncan multiple range test; $\mathrm{F}_{0}$ : minimum fluorescence; FNR: ferredoxin-NADP ${ }^{+}$-reductase; $F_{m}$ : maximum fluorescence; $F_{v} / F_{m}$ : maximum quantum yield of primary photochemistry; PI: performance index; PPFD: photosynthetic photon flux density; PS2: Photosystem II; T: temperature; $\mathrm{T}_{\mathrm{c}}$ : critical temperature; $\mathrm{Q}_{\mathrm{A}}$ : primary quinone electron acceptors of PS2

\section{INTRODUCTION}

The light energy absorbed by the chlorophyll pigments can be used to drive photosynthesis (photochemistry), be dissipated as heat, or be re-emitted as light (chlorophyll- $a$ fluorescence). These three processes are in competition. Any efficiency increase in one of them will result in a yield decline of the other two processes (Boureima et al. 2012; Murchie and Lawson 2013; Kargar et al. 2019). Chlorophyll- $a$ fluorescence (CF) measurement is a nondestructive method (Guidi and Calatayud 2014) that is widely used for detecting the plant stress level caused by environmental factors including salt (Tsai et al. 2019; Zushi and Matsuzoe 2017), drought (Azhar et al. 2013; Boureima et al. 2012; Falqueto et al. 2017; Gholamin and Khayatnezhad 2011; Jedmowski et al. 2015; Mishra et al. 2016), temperature (Jedmowski et al. 2015), and shading
(Ulqodry et al. 2014). It reflects the photochemical efficiency (Çiçek and Arslan 2015; Kalaji et al. 2014; Stirbet and Govindjee 2011) and provides quick information about the chloroplast electron transport chain functionality (Jedmowski et al. 2015).

Parameters of chlorophyll- $a$ fluorescence measurement that are widely used to determine the drought tolerance levels of some genotypes are performance index (PI) and maximum quantum yield of primary photochemistry $\left(\mathrm{F}_{\mathrm{v}} / \mathrm{F}_{\mathrm{m}}\right)$. These parameters have been used to determine the drought-tolerant level of some genotypes of some plant species, for example, rubber (Azhar et al. 2013; Falqueto et al. 2017), maize (Gholamin and Khayatnezhad 2011), and sesame (Boureima et al. 2012). PI provides quantitative information about plant vitality. PI is produced by three independent parameters: the concentration of reaction centers per chlorophyll, a parameter related to primary 
photochemistry, and a parameter related to electron transport (Kalaji et al. 2016). Therefore, the PI value is influenced by the $F_{v} / F_{m}$ value. PI measurement will be accurate when dark adaptation time is well defined and optimal $F_{v} / F_{m}$ is achieved (Guidi et al. 2019). $F_{v}$ is the difference between the maximum $(\mathrm{Fm})$ and minimum fluorescence $\left(\mathrm{F}_{0}\right)$ of dark-adapted leaves (Kalaji et al. 2014).

Measurement of chlorophyll- $a$ fluorescence on rubber plant conducted by Falqueto et al. (2017) found that the RRIM 600 rubber clone showed an advantage over the FX3864 clone in utilizing energy under water shortage conditions. Furthermore, RRIM 600 is also categorized as a rubber drought tolerant clone (Krishan 2017; Luke et al. 2015; Thomas et al. 2015). Besides RRIM 600, GT1 was reported to have more tolerance to drought (An et al. 2011; Ardika et al. 2011). In contrast, PB 260 was reported to be more sensitive to drought (Inonu et al. 2011; Sanier et al. 2013).

Chlorophyll- $a$ fluorescence transient can be measured by exposing the dark-adapted leaf to high light intensity. Dark adaptation of the leaf is aimed to decrease the light intensity needed to fully saturate the photochemical quenching, hence optimum $\mathrm{F}_{\mathrm{v}} / \mathrm{F}_{\mathrm{m}}$ can be achieved. The duration of dark adaptation needed for accurate chlorophyll- $a$ fluorescence transient measurement might be varied depending on the plant species (Stirbet et al. 2018).

Measurement of chlorophyll- $a$ fluorescence to determine the drought factor index requires a dark adaptation of the leaf. Dark adaptation is needed to achieve the correct $\mathrm{F}_{0}$ level. The correct $\mathrm{F}_{0}$ level is achieved when the first stable electron acceptor of PS2 is fully oxidized (Hansatech Instrument Ltd 2018). The dark adaptation duration needed for accurate chlorophyll- $a$ fluorescence measurement might be varied depending on the plant species (Stirbet et al. 2018). The duration required for dark adaptation is related to FNR (Ferredoxin-NADP ${ }^{+}$reductase) inactivation. FNR inactivation time varies between plant species, for example, 15 min for peas and one hour for Pinus species (Kalaji et al. 2014).

The dark adaptation of leaf samples during daylight can be conducted by using leaf clips. The usage of leaf clips might increase the leaf temperature due to a block of transpiration. The high leaf temperature results in underestimation of PS2 efficiency measurement results because $F_{0}$ is influenced rapidly by the high temperature. The temperature when the $\mathrm{F}_{0}$ starts to increase dramatically is called $T_{c}$ (Giorio 2011). $T_{c}$ is different for different plant species and environmental conditions. Therefore, under sunlight exposure, the duration of dark adaptation using leaf clips should be done as quickly as possible to obtain accurate chlorophyll- $a$ fluorescence measurement results. In addition, the use of leaf clips is time-consuming and limits the measurement of chlorophyll- $a$ fluorescence parameters on a large population for genetic analyses. Measurement at night is an alternative to avoid the constraints associated with the use of leaf clips. This study aimed to determine the most suitable time for conducting the chlorophyll- $a$ fluorescence measurement. Hence, the alternative time and length of duration of dark adaptation using leaf clips if the measurement to be conducted at night are not possible were also studied.

\section{MATERIALS AND METHODS}

\section{Experimental site and plant materials}

This study was conducted from January 19 to February 3 , 2021, in the greenhouse located at $02^{\circ} 55^{\prime} 40^{\prime \prime} \mathrm{S}$ and $104^{\circ} 32$ ' 16 " E with an altitude of $10 \mathrm{~m}$ above sea level. The greenhouse belongs to the Indonesian Rubber Research Institute, Sembawa, South Sumatra, Indonesia. The plant materials consisted of four rubber clones, namely RRIM 600, GT1, SP 217, and PB 260. All of the planting materials were three months old and the leaves were in fully expanded leaf stage with atLEAF CHL PLUS chlorophyll index between 53.0 and 67.1. Four leaf samples from each of rubber clones were used for biological replicates. The planting materials and the position of the leaves samples as replicates are presented in Figure 1. All plant materials were planted in the $15 \times 10$ $\mathrm{cm}^{2}$ size pots filled with cocopeat as the planting medium. The planting medium moisture content in each pot was maintained at available levels for plants by adding $120 \mathrm{~mL}$ of water into the pots twice a week.

\section{Microclimate data}

The microclimate data inside the greenhouse was recorded using Licor Li-189 (LI-COR, Inc., 1990) for the photosynthetic photon flux density $\left(\mu \mathrm{mol} \mathrm{m}^{-2} \mathrm{~s}^{-1}\right)$, automatic thermohygrometer MiSol DS102 for the room temperature $\left({ }^{\circ} \mathrm{C}\right)$ and humidity $(\%)$, and thermo gun (CEM DT-8806S) for the leaf temperature $\left({ }^{\circ} \mathrm{C}\right)$.

\section{Chlorophyll index and chlorophyll-a fluorescence measurement}

The chlorophyll index was measured using atLEAF CHL PLUS chlorophyll meter (FT GREEN LLC 2019). This device used 640 and $940 \mathrm{~nm}$ wavelengths of lightemitting diodes that were transmitted through the leaf (FT GREEN LLC 2019). atLEAF CHL PLUS provided an accurate estimation of the chlorophyll index for rubber trees (Cahyo et al. 2020). The chlorophyll index was measured once before the measurement of the chlorophyll$a$ fluorescence. Furthermore, the chlorophyll- $a$ fluorescence parameters namely $\mathrm{PI}, \mathrm{Fv} / \mathrm{Fm}$, and $\mathrm{F}_{0}$ were measured with a Pocket PEA (Hansatech Instrument Ltd 2018) with saturating light pulses of $3500 \mu \mathrm{mol} \mathrm{m}^{-2} \mathrm{~s}^{-1}$ for 1 s (Hansatech Instrument Ltd 2018). The saturating light pulses of $3500 \mu \mathrm{mol} \mathrm{m} \mathrm{m}^{-2} \mathrm{~s}^{-1}$ was the default light pulse used by the Pocket PEA tool. Both chlorophyll index and chlorophyll- $a$ fluorescence measurements were conducted at the same point in the same leaf.

A parameter of chlorophyll- $a$ fluorescence transient widely used to determine the plant environmental stress tolerance level is PI. The PI value is influenced by the measured value of $F_{v} / F_{m}$. Adequate time is achieved when $\mathrm{F}_{\mathrm{v}} / \mathrm{F}_{\mathrm{m}}$ values are stable. Therefore, in this study, the parameter of chlorophyll- $a$ fluorescence transient that was used to determine the best time for chlorophyll- $a$ fluorescence transient measurement was $\mathrm{F}_{\mathrm{v}} / \mathrm{F}_{\mathrm{m}}$. 


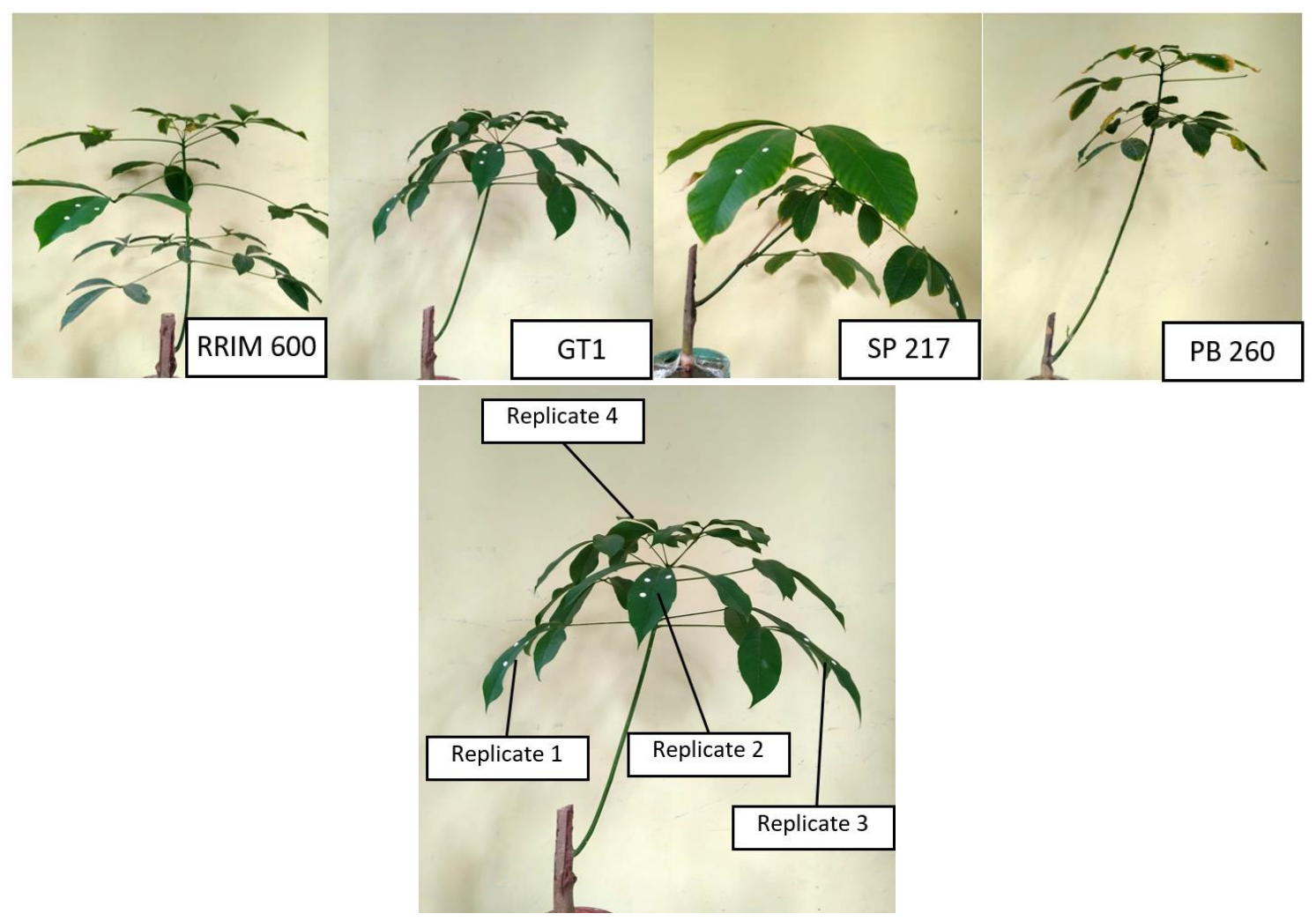

Figure 1. The planting materials and the positions of the leaves samples as replicates

This study consisted of two steps. The first step was to determine the suitable time for chlorophyll- $a$ fluorescence measurement without using leaf clips to darken the leaf at night. This step consisted of conducting measurements at five different times: 7.30, 8.00, 8.30, 9.00, and 9.30 p.m., respectively. The second step aimed to determine the alternative time for chlorophyll- $a$ fluorescence measurement using leaf clips to darken the leaf if the measurement at night is not possible. The second step consisted of two factors. The first factor was the measurement time, which was divided into two categories: 7.30 a.m. and 1.30 p.m. The second factor was the duration of dark adaptation using leaf clips, which consisted of nine groups, namely $0,15,30,45,60,75,90,105$, and $120 \mathrm{~min}$. Based on results of the first step, an additional treatment (measurement at 9.00 p.m. without using leaf clips to darken the leaf) was used as a control. At the end of each measurement, the leaf temperature at the point where the clip was placed was measured.

\section{Statistical analysis}

Completely Randomized Block Design with an additional treatment as a control analysis of variance was used to analyze the effect of the treatment of the observed variable. After that, Duncan Multiple Range Test (DMRT) was employed with significance level of $95 \%$ to differentiate the means of each variable. This statistical analysis was conducted using the SAS version 9 program software (SAS Institute Inc. 2002).

\section{RESULTS AND DISCUSSION}

The best time for chlorophyll- $a$ fluorescence at night

The results of $\mathrm{F}_{\mathrm{v}} / \mathrm{F}_{\mathrm{m}}$ and PI measurement on four rubber clones at various times without using leaf clips for dark adaptation are presented in Figure 2. Furthermore, the chlorophyll index of the measured leaves is presented in Figure 3.

Figure 2 shows that the stable $F_{v} / F_{m}$ and PI for all clones were achieved when the measurements were conducted at $8.30,9.15$, and 9.30 p.m. $F_{v} / F_{m}$ and PI for all clones increased before 8.30 p.m. and leveled off after 8.30 p.m. It indicated that two hours of natural dark adaptation period (sunset was at 6.30 p.m.) was sufficient for the FNR inactivation of the four rubber clones. Furthermore, although the chlorophyll index of RRIM 600 was lower than the other clones, the optimal dark adaptation period was the same as the other clones. It could happen because overall the chlorophyll index of all clones was likely uniform (Figure 3).

The two hours duration of dark adaptation was needed by the plants after being exposed to high light intensity. In this study, the Photosynthetic Photon Flux Density (PPFD) received from sunlight reached $87.82 \mu \mathrm{mol} \mathrm{m} \mathrm{m}^{-2} \mathrm{~s}^{-1}$ in the afternoon (Table 1). Under high light intensity, an electron acceptor of $\mathrm{Q}_{\mathrm{A}}$ was more reductive and required more time to fully oxidize $\mathrm{Q}_{\mathrm{A}}$ compared to under low light intensity conditions (Sasaki et al., 1994). Hence, at 8.30 p.m. (two hours after sunset), measurement of chlorophyll- $a$ fluorescence can be conducted and resulted in optimum and stable values of $F_{v} / F_{m}$ and PI. 

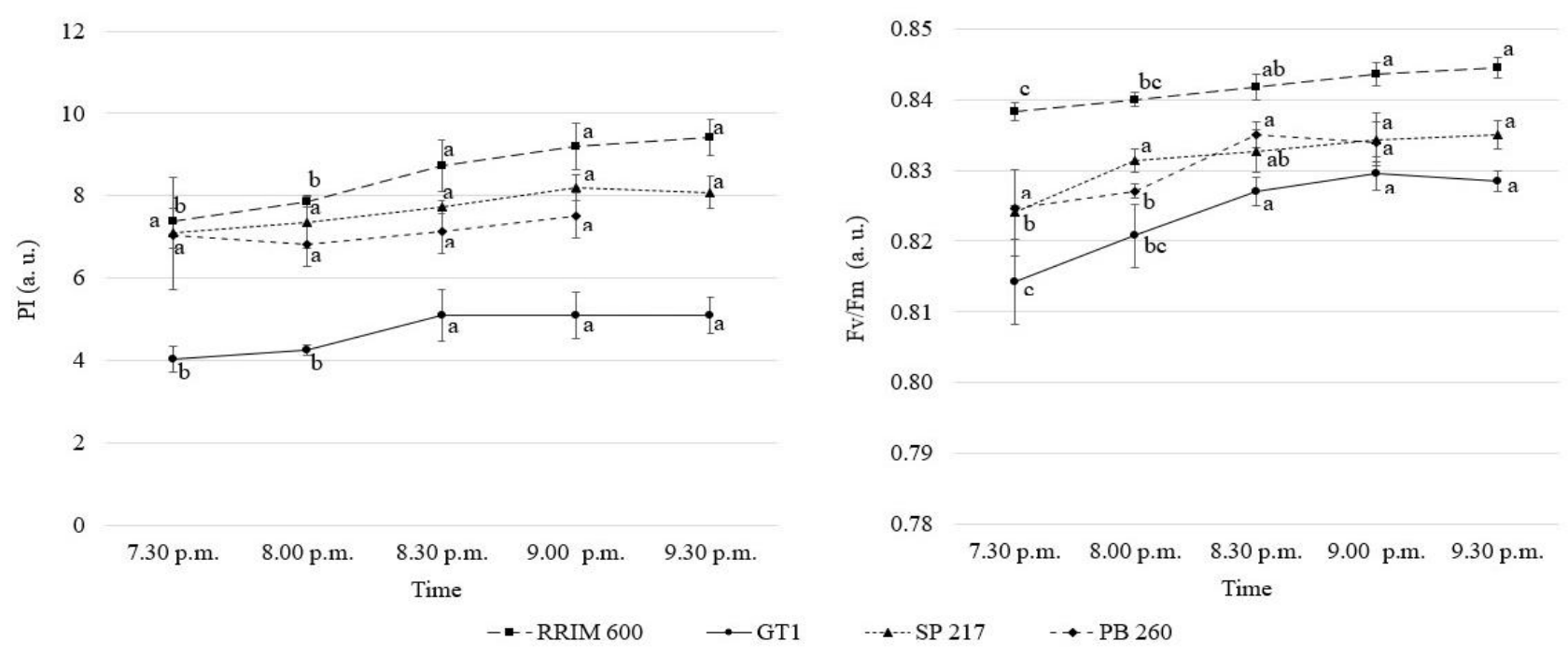

Figure 2. Effect of measurement time without the dark adaptation using leaf clip-on $\mathrm{F}_{\mathrm{v}} / \mathrm{F}_{\mathrm{m}}$ and Performance Index (PI). a.u., arbitrary unit. Note: The different letter within the same clone indicates significantly different groups determined by the Duncan test $(\mathrm{P}<0.05)$ with the number of samples $(\mathrm{n})=4$

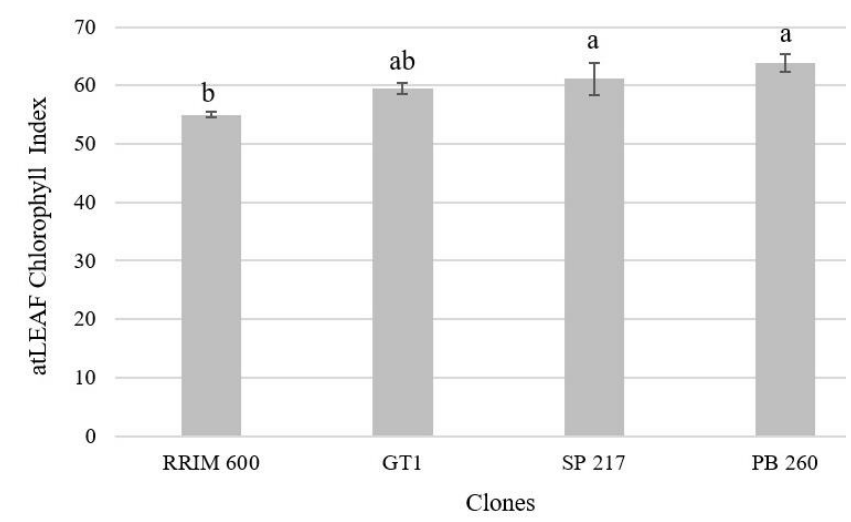

Figure 3. atLEAF chlorophyll index of four rubber clones. Note: The different letter indicates significantly different groups determined by the Duncan test $(\mathrm{P}<0.05)$ with the number of samples $(\mathrm{n})=4$

Furthermore, between 8.30 p.m. and 9.30 p.m, the PPFD was at $0.01 \mu \mathrm{mol} \mathrm{m} \mathrm{m}^{-2} \mathrm{~s}^{-1}$ and the change of room temperature was lower than $0.5{ }^{\circ} \mathrm{C}$ (Figure 4), hence the measurement results error could be suppressed. Stable leaf temperature was expected to result in stable $F_{0}$ value, because the dramatic change of the temperature could affect the value of $F_{0}$ parameter (Giorio 2011; Giorio et al. 2012). In this study, the fluctuation of leaves temperature at both day and night-time was relatively small and the maximum temperature at day-time was still lower than 34 ${ }^{\circ} \mathrm{C}$ (Figure 5). Hence, it had a weak correlation with the fluctuation of $\mathrm{F}_{0}$ (Table 2). It can happen because the temperature was still below $\mathrm{T}_{\mathrm{c}}$ (critical temperature). The temperature will significantly affect $\mathrm{F}_{0}$ when it rises above the $\mathrm{T}_{\mathrm{c}}$ (Giorio 2011). However, in general, the measurement of chlorophyll- $a$ fluorescence for a large population (for example, screening progenies population) is better to be conducted at night-time, starting from 8.30 p.m. to avoid high PPFD and excess fluctuation of leaf temperature that can underestimate the measurement results.

Measurement on chlorophyll- $a$ fluorescence of four rubber clones using various times and duration of dark adaptation revealed that the dark adaptation duration using leaf clips needed for chlorophyll- $a$ fluorescent transient measurement between the rubber clones were different. Furthermore, when the measurements were conducted during nighttime starting at 8.30 p.m. (two hours after sunset), the dark adaptation treatments using leaf clips were not needed for all clones because the PPFD was very low. In addition, the chlorophyll- $a$ fluorescence measurement will be faster if it is conducted during nighttime. Fast measurement is needed for a large population (Murchie and Lawson 2013) in order to avoid the micro-climate change during the measurement of chlorophyll- $a$ fluorescent transient.

\section{Alternative time for chlorophyll- $a$ fluorescence measurement}

To obtain accurate chlorophyll- $a$ fluorescence measurement, the measurement can be conducted at nighttime, starting at 8.30 p.m. without dark adaptation period using leaf clips. As an alternative, during daytime, measurement of chlorophyll- $a$ fluorescence can also be conducted using leaf clips to cover the leaf; hence the leaf is in dark condition for specific times. The results of this measurement are presented in Table 3. 


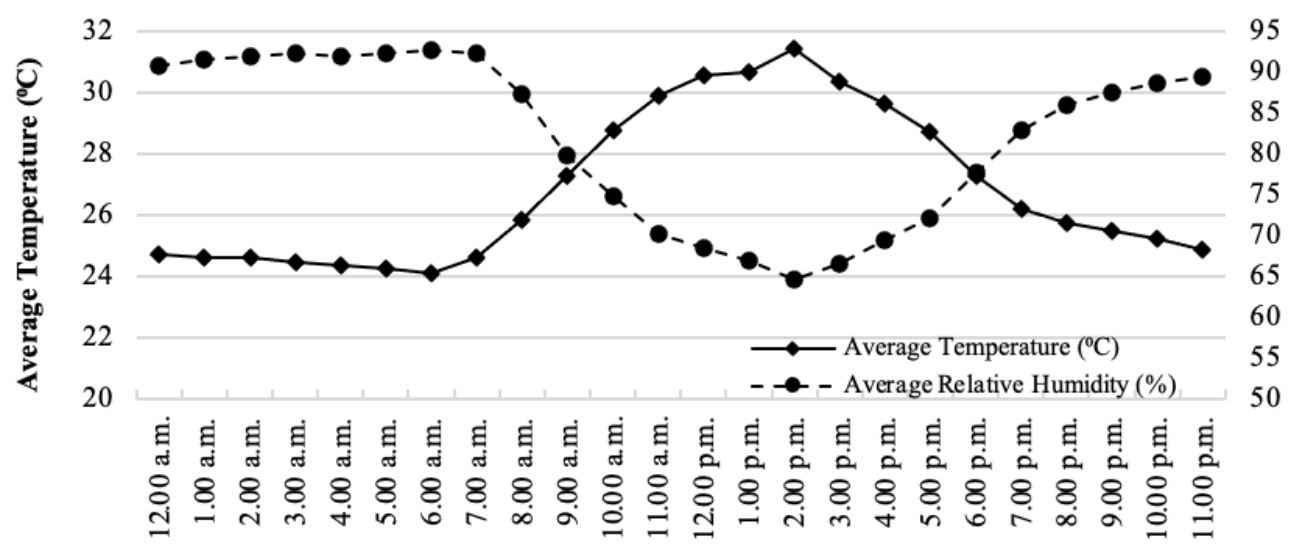

Time

Figure 4. Average temperature $\left({ }^{\circ} \mathrm{C}\right)$ and relative humidity $(\%)$ during 16 days of chlorophyll- $a$ fluorescence measurement

Table 1. Photosynthetic Photon Flux Density (PPFD) $\left(\mu \mathrm{mol} \mathrm{m} \mathrm{m}^{-2} \mathrm{~s}^{-1}\right)$ inside the greenhouse

\begin{tabular}{|c|c|c|c|c|c|c|c|c|c|}
\hline \multirow{2}{*}{ Time } & \multicolumn{9}{|c|}{ Duration of dark adaptation (min) } \\
\hline & $\mathbf{0}$ & 15 & 30 & 45 & 60 & 75 & 90 & 105 & 120 \\
\hline Morning (7.30 a.m.) & 29.58 & 2.24 & 17.51 & 35.95 & 29.45 & 5.27 & 29.70 & 32.44 & 22.26 \\
\hline Afternoon (1.30 p.m.) & 77.60 & 39.92 & 87.82 & 73.73 & 11.71 & 55.88 & 73.57 & 43.39 & 66.73 \\
\hline Night (9.00 p.m.) & 0.01 & & & & & & & & \\
\hline
\end{tabular}

Table 2. Correlation (r) between temperature $\left({ }^{\circ} \mathrm{C}\right)$ and $\mathrm{F}_{0}$ (a.u.) of four rubber clones

\begin{tabular}{|c|c|c|c|c|c|c|c|c|c|}
\hline \multirow[b]{2}{*}{ Clones } & \multicolumn{3}{|c|}{ Morning } & \multicolumn{3}{|c|}{ Afternoon } & \multicolumn{3}{|c|}{ Night } \\
\hline & $\begin{array}{c}\text { Average } \\
\text { T }\left({ }^{\circ} \mathrm{C}\right)\end{array}$ & $\begin{array}{l}\text { Average } \\
F_{0} \text { (a.u.) }\end{array}$ & $\begin{array}{c}\text { Correlation } \\
\text { (r) between } \mathbf{T} \\
\text { and } \mathbf{F}_{0}\end{array}$ & $\begin{array}{c}\text { Average T } \\
\quad\left({ }^{\circ} \mathrm{C}\right)\end{array}$ & $\begin{array}{l}\text { Average } \\
\text { Fo }_{0} \text { (a.u.) }\end{array}$ & $\begin{array}{c}\text { Correlation } \\
\text { (r) between } \\
\mathbf{T} \text { and } \mathbf{F}_{\mathbf{0}} \\
\end{array}$ & $\begin{array}{c}\text { Average } \\
\text { T }\left({ }^{\circ} \mathbf{C}\right)\end{array}$ & $\begin{array}{l}\text { Average } \\
\text { Fo }_{0} \text { (a.u.) }\end{array}$ & $\begin{array}{c}\text { Correlation } \\
(\mathbf{r}) \text { between } \\
\mathrm{T} \text { and } \mathrm{F}_{\mathbf{0}} \\
\end{array}$ \\
\hline RRIM 600 & 26.09 & 6156 & -0.15 & 29.82 & 6424 & 0.23 & 25.77 & 5906 & 0.22 \\
\hline GT1 & 26.56 & 7549 & 0.08 & 30.61 & 7777 & 0.44 & 25.73 & 6956 & -0.01 \\
\hline SP 217 & 26.17 & 6853 & -0.24 & 30.27 & 7110 & 0.17 & 25.60 & 6405 & 0.06 \\
\hline PB 260 & 26.23 & 6415 & -0.35 & 30.33 & 6741 & 0.16 & 25.75 & 6328 & -0.56 \\
\hline
\end{tabular}

Note: T: temperature; a.u.: arbitrary unit, number of samples $(\mathrm{n})=4$

Table 3. Effect of measurement time and some duration of dark adaptation using leaf clip on $\mathrm{F}_{\mathrm{v}} / \mathrm{F}_{\mathrm{m}}$ of four rubber clones

\begin{tabular}{|c|c|c|c|c|c|c|c|c|c|c|c|c|c|c|c|}
\hline \multirow{2}{*}{ Time } & \multicolumn{15}{|c|}{ Duration of dark adaptation (min) } \\
\hline & $\mathbf{0}$ & & 1 & & 30 & & 45 & & 6 & & 75 & & 90 & 105 & 120 \\
\hline \multicolumn{16}{|l|}{ RRIM 600} \\
\hline Morning (7.30 a.m.) & 0.802 & $\mathrm{i}$ & 0.839 & c-e & 0.841 & $b-d$ & 0.843 & $a-c$ & 0.842 & $\mathrm{~b}-\mathrm{c}$ & 0.844 & $a-c$ & 0.847 a & 0.841 b-d & 0.846 a-b \\
\hline Afternoon (1.30 p.m.) & 0.764 & $\mathrm{j}$ & 0.829 & g-h & 0.829 & g-h & 0.833 & f-g & 0.836 & $e-f$ & 0.837 & $d-f$ & $0.837 \mathrm{~d}-\mathrm{f}$ & 0.836 e-f & $0.827 \mathrm{~h}$ \\
\hline Night (9.00 p.m.) & 0.843 & $\mathrm{a}-\mathrm{c}$ & & & & & & & & & & & & & \\
\hline \multicolumn{16}{|l|}{ GT1 } \\
\hline Morning (7.30 a.m.) & 0.778 & $\mathrm{~h}$ & 0.820 & $\mathrm{a}-\mathrm{c}$ & 0.810 & c-e & 0.807 & d-e & 0.820 & $\mathrm{a}-\mathrm{c}$ & 0.824 & $a-b$ & 0.813 b-e & $0.821 \mathrm{a}-\mathrm{c}$ & $0.823 \mathrm{a}-\mathrm{b}$ \\
\hline Afternoon (1.30 p.m.) & 0.729 & $\mathrm{i}$ & 0.808 & d-e & 0.790 & $\mathrm{~g}$ & 0.795 & $\mathrm{f}-\mathrm{g}$ & 0.815 & b-d & 0.816 & b-d & 0.802 e-f & $0.813 b-d$ & 0.807 d-e \\
\hline Night (9.00 p.m.) & 0.829 & $\mathrm{a}$ & & & & & & & & & & & & & \\
\hline \multicolumn{16}{|l|}{ SP 217} \\
\hline Morning (7.30 a.m.) & 0.775 & $\mathrm{f}$ & 0.821 & $a-e$ & 0.819 & a-e & 0.822 & a-e & 0.821 & a-e & 0.830 & $a-b$ & 0.825 a-d & $0.828 \mathrm{a}-\mathrm{c}$ & 0.829 a-b \\
\hline Afternoon (1.30 p.m.) & 0.752 & $\mathrm{~g}$ & 0.811 & d-e & 0.808 & $\mathrm{e}$ & 0.810 & d-e & 0.821 & a-e & 0.812 & c-e & $0.813 \mathrm{c}-\mathrm{e}$ & 0.820 a-e & 0.816 b-e \\
\hline Night (9.00 p.m.) & 0.834 & $\mathrm{a}$ & & & & & & & & & & & & & \\
\hline \multicolumn{16}{|l|}{ PB 260} \\
\hline Morning (7.30 a.m.) & 0.785 & $\mathrm{~g}$ & 0.824 & $\mathrm{~b}-\mathrm{c}$ & 0.820 & $\mathrm{c}$ & 0.824 & $b-c$ & 0.832 & $\mathrm{a}-\mathrm{b}$ & 0.834 & $\mathrm{a}$ & $0.831 \mathrm{a}-\mathrm{b}$ & $0.832 \mathrm{a}$ & $0.831 \mathrm{a}-\mathrm{b}$ \\
\hline Afternoon (1.30 p.m.) & 0.740 & $\mathrm{~h}$ & 0.812 & $\mathrm{~d}$ & 0.796 & $\mathrm{f}$ & 0.805 & $\mathrm{e}$ & 0.824 & $\mathrm{~b}-\mathrm{c}$ & 0.823 & $\mathrm{c}$ & $0.813 \mathrm{~d}$ & $0.821 \mathrm{c}$ & 0.811 d-e \\
\hline Night (9.00 p.m.) & 0.834 & $\mathrm{a}$ & & & & & & & & & & & & & \\
\hline
\end{tabular}

Note: The different letter within the same clone indicates significantly different groups determined by the Duncan test $(\mathrm{P}<0.05)$ with number of samples $(n)=4$ 
Table 3 shows that optimum $F_{\mathrm{v}} / \mathrm{F}_{\mathrm{m}}$ for GT1, SP 217, and PB 260 were about 0.83 , whereas for RRIM 600 was about 0.84. Furthermore, in the morning time, PB 260 required $60 \mathrm{~min}$, whereas other clones required $15 \mathrm{~min}$ to achieve optimum $\mathrm{F}_{\mathrm{v}} / \mathrm{F}_{\mathrm{m}}$. Furthermore, in the afternoontime, almost all of the clones did not achieve optimum value of $F_{v} / F_{m}$ until 120 min of duration of dark adaptation except SP 217. SP 217 achieved optimum $F_{v} / F_{m}$ at $60 \mathrm{~min}$ of duration of dark adaptation.

The dramatic microclimate changes during measurement of chlorophyll- $a$ fluorescent transient could affect the measurement result. In the daytime, the PPFD fluctuated between $2.23-87.82 \mu \mathrm{mol} \mathrm{m}^{-2} \mathrm{~s}^{-1}$ (Table 1) and the change of the room temperature during one hour could be more than $1{ }^{\circ} \mathrm{C}$ (Figure 4). The high leaf temperature induced underestimate of PS2 efficiency measurement results (Giorio 2011; Giorio et al. 2012). The change of temperature can affect the accuracy of chlorophyll- $a$ fluorescent transient measurement. This could happen because $\mathrm{F}_{0}$ was influenced rapidly by high leaf temperature, especially when the leaf temperature rising from 25 to $50{ }^{\circ} \mathrm{C}$ (Giorio 2011). In this research, leaf temperature fluctuated between $24.28-28.83{ }^{\circ} \mathrm{C}$ in the morning and $26.10-33.93{ }^{\circ} \mathrm{C}$ in the afternoon (Figure 5).
This range of leaves temperatures was still lower than $T_{c}$, hence the $\mathrm{F}_{0}$ values were not significantly influenced by the change of leaves temperature.

In this research, instead of leaf temperature, the main factor that influenced $F_{0}$ was photosynthetic photon flux density (PPFD) from sunlight (Table 1). Table 1 also shows that the highest PPFD was observed in the afternoon, hence the highest $F_{0}$ was obtained by measurement of chlorophyll- $a$ fluorescence conducted in the afternoon at 0 minute of duration of dark adaptation (Table 4).

Table 4 shows the chlorophyll- $a$ fluorescence measurement of the leaves from four different rubber clones at 9.00 p.m. resulted in a minimum value of $F_{0}$ that was significantly lower than $\mathrm{F}_{0}$ values measured at day time without dark adaptation using leaf clip for all clones. Similar results were reported by Ögren and Sjöström (1990), stating that the measurement of chlorophyll- $a$ fluorescence on a clear day resulted in a decrease of $F_{m}$ and an increase in $F_{0}$. It indicates that at 9.00 p.m. the $Q_{A}$ has been fully oxidized. Hence, the measurement of chlorophyll- $a$ fluorescence resulted in the value of the correct parameter. Therefore, measurement of chlorophyll$a$ fluorescence transient is more suitable to be conducted at night.

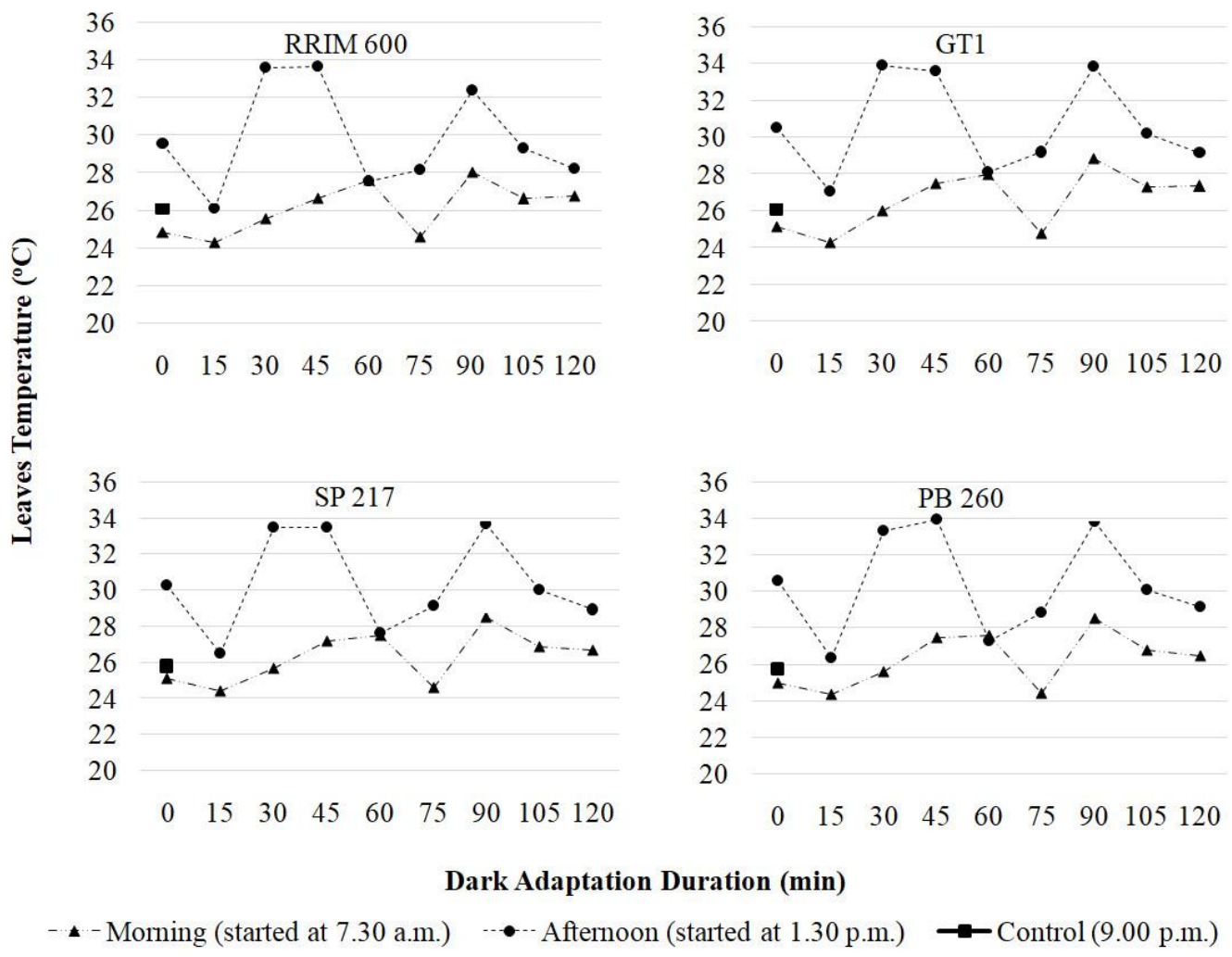

Figure 5. The fluctuation of leaves temperature during chlorophyll- $a$ fluorescence measurement 
Table 4. Effect of measurement time and some duration of dark adaptations on $\mathrm{F}_{0}$ of four rubber clones

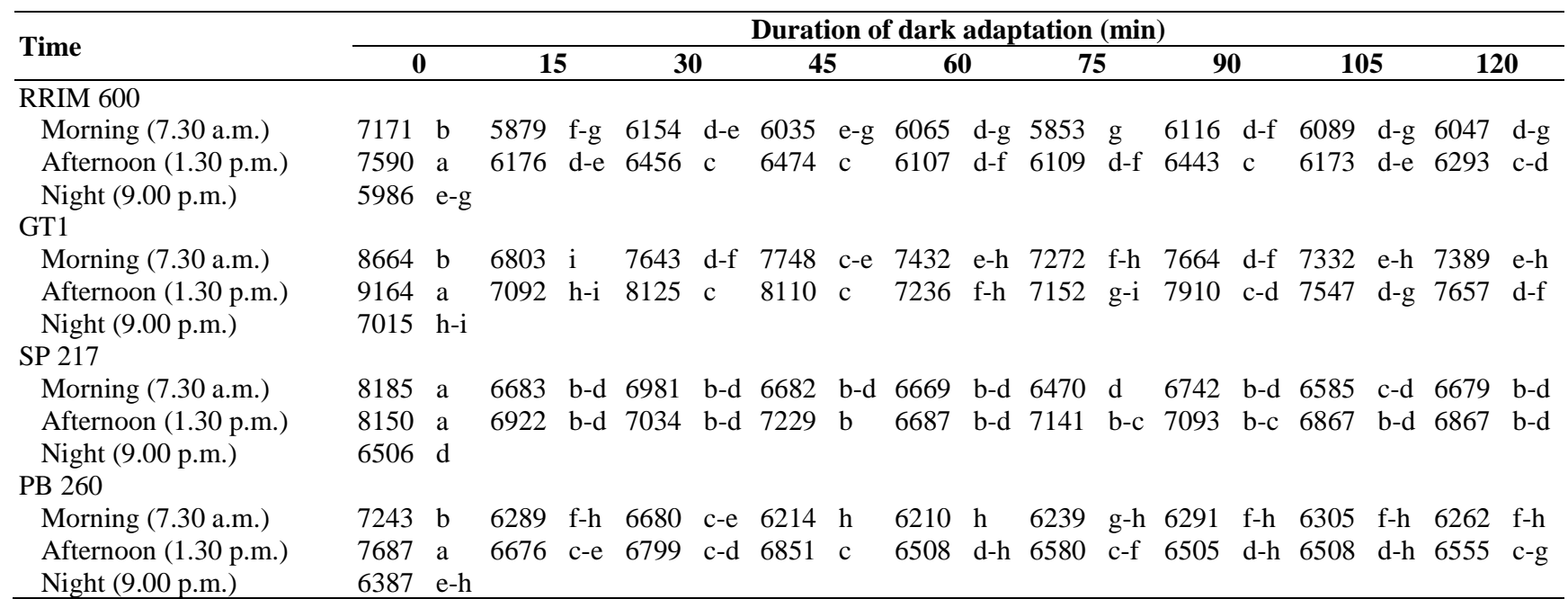

Note: The different letter within the same clone indicates significantly different groups determined by the Duncan test $(\mathrm{P}<0.05)$ with the number of samples $(\mathrm{n})=4$

In conclusion, the higher the PPFD received by the leaves, the longer the duration of dark adaptation needed to obtain the correct value of chlorophyll- $a$ fluorescence parameter. Therefore, before the measurement of chlorophyll- $a$ fluorescence transient, rubber leaves should be dark- $a$ dapted at a specific time. This study found that a dark adaptation time of two hours after sunset was long enough for the rubber leaves chlorophyll- $a$ fluorescence transient measurement without using the leaf clips for dark adaptation. If the measurement is conducted by 7.30 a.m., the clone RRIM 600, GT1, and SP 217 required 15 min of dark adaptation, whereas clone PB 260 required $60 \mathrm{~min}$ of dark adaptation. Furthermore, the measurement of chlorophyll- $a$ fluorescence in the afternoon is not recommended because most rubber clones could not achieve the optimum $\mathrm{F}_{\mathrm{v}} / \mathrm{F}_{\mathrm{m}}$. To avoid excessive fluctuations of leaf temperature, high PPFD, and waiting time for rubber leaf dark adaptation, chlorophyll- $a$ fluorescence measurement can be conducted at night-time, two hours after sunset. This procedure offers the possibility for high-throughput phenotyping of large rubber genetic populations for eco-physiological parameters requiring PI and $\mathrm{F}_{\mathrm{v}} / \mathrm{F}_{\mathrm{m}}$ determination.

\section{ACKNOWLEDGEMENTS}

The authors thank SEARCA for the PhD scholarship granted to the first author, Nusantara Program and French Embassy for funding the Rubber Omics Project Number 43203NG, and the Indonesian Rubber Research Institute, Banyuasin, Indonesia for providing the place, equipment, and planting materials for this study.

\section{REFERENCES}

An F, Kong L, Gong L, Wang Z, Lin W. 2011. Involvement of rootstocks and their hydraulic conductance in the drought resistance of grafted rubber trees. Afr J Biotechnol 10 (51): 10393-10404. DOI: 10.5897/AJB11.354

Ardika R, Cahyo AN, Wijaya, T. 2011. Wintering and Yield Dynamics on Various Rubber Clones and Their Relationship to Soil Water Content. Indones J Nat Rubber Res 29 (2): 102-109.

Azhar A, Sathornkich J, Rattanawong R, Kasemsap P. 2013. Responses of Chlorophyll fluorescence, stomatal conductance, and net photosynthesis rates of four rubber (Hevea brasiliensis) Genotypes to Drought. Adv Mater Res 844: 11-14. DOI: 10.4028/www.scientific.net/AMR.844.11

Boureima S, Oukarroum A, Diouf M, Cisse N, Van Damme P. 2012. Screening for drought tolerance in mutant germplasm of sesame (Sesamum indicum) probing by chlorophyll- $a$ fluorescence. Environ Exp Bot 81: 37-43. DOI: 10.1016/j.envexpbot.2012.02.015

Cahyo AN, Murti RH, Putra ETS, Nuringtyas TR, Fabre D, Montoro P. 2020. SPAD-502 and atLEAF CHL PLUS values provide good estimation of the chlorophyll content for Hevea brasiliensis Müll. Arg. leaves. Menara Perkebunan 88 (1): 1-8. DOI: 10.22302/iribb.jur.mp.v88i1.369

Çiçek N, Arslan Ö. 2015. Are The Photosynthetic Performance Indexes and The Drought Factor Index Satisfactory Selection Criterion for Stress? Fresenius Environ Bull 24 (11): 4190-4198.

Falqueto AR, da Silva Júnior RA, Gomes MTG, Martins JPR, Silva DM, Partelli FL. 2017. Effects of drought stress on chlorophyll-a fluorescence in two rubber tree clones. Sci Hortic 224: 238-243. DOI: 10.1016/j.scienta.2017.06.019

FT GREEN LLC. 2019. atLEAF CHL PLUS Chlorophyll Meter User Manual 0131-50 Ver 1.1.

Gholamin R, Khayatnezhad M. 2011. The effect of end season drought stress on the chlorophyll content, chlorophyll fluorescence parameters and yield in maize cultivars. Sci Res Essays 6 (25): 5351-5357. DOI: 10.5897/SRE11.914

Giorio P. 2011. Black leaf clips increased minimum fluorescence emission in clipped leaves exposed to high solar radiation during dark adaptation. Photosynthetica 49 (3): 371-379. DOI: 10.1007/s11099011-0040-0

Giorio P, Nuzzo V, Guida G, Albrizio, R. 2012. Black leaf clips of a commercial fluorometer increased leaf temperature during dark adaptation under high solar radiation. Photosynthetica 50 (3): 467471. DOI: $10.1007 / \mathrm{s} 11099-012-0042-6$ 
Guidi L, Calatayud A. 2014. Non-invasive tools to estimate stress-induced changes in photosynthetic performance in plants inhabiting Mediterranean areas. Environ Exp Bot 103: 42-52. DOI: 10.1016/j.envexpbot.2013.12.007

Guidi L, Lo Piccolo E, Landi, M. 2019. Chlorophyll Fluorescence, Photoinhibition and Abiotic Stress: Does it Make Any Difference the Fact to Be a C3 or C4 Species? Front Plant Sci 10 (174): 1-11. DOI: 10.3389/fpls.2019.00174

Hansatech Instrument Ltd. 2018. Handy PEA+ and Pocket PEA System Manual.

Inonu I, Budianta D, Umar M, Yakup, Wiralag AYA. 2011. Rubber clone response on irrigation frequency in sand tailing medium post thin mining. J Agron Indones 39 (2): 131-136.

Jedmowski C, Ashoub A, Momtaz O, Brüggemann W. 2015. Impact of Drought, Heat, and Their Combination on Chlorophyll Fluorescence and Yield of Wild Barley (Hordeum spontaneum). J Bot 2015: 1-9. DOI: $10.1155 / 2015 / 120868$

Kalaji HM, Jajoo A, Oukarroum A, Brestic M, Zivcak M, Samborska IA Cetner MD, Łukasik I, Goltsev V, Ladle RJ. 2016. Chlorophyll- $a$ fluorescence as a tool to monitor physiological status of plants under abiotic stress conditions. Acta Physiol Plant 38 (102): 1-11. DOI: 10.1007/s11738-016-2113-y

Kalaji HM, Schansker G, Ladle RJ, Goltsev V, Bosa K, Allakhverdiev SI, Brestic M, Bussotti F, Calatayud A, Dąbrowski P, Elsheery NI, Ferroni L, Guidi L, Hogewoning SW, Jajoo A, Misra AN, Nebauer SG, Pancaldi S, Penella C, Poli D, Pollastrini M, Romanowska-Duda ZB, Rutkowska B, Serôdio J, Suresh K, Szulc W, Tambussi E, Yanniccari M, Zivcak M. 2014. Frequently asked questions about in vivo chlorophyll fluorescence: practical issues. Photosynth Res 122 (2): 121-158. DOI: 10.1007/s11120-014-0024-6

Krishan B. 2017. Assessment of drought tolerance in few clones of natural rubber (Hevea brasiliensis) under dry hot climate of Odisha, India. J Exp Biol Agric Sci 5 (1): 106-110. DOI: 10.18006/2017.5(1).106.110

LI-COR Inc. 1990. LI-189 Quantum/Radiometer/Photometer Operating Manual.

Luke LP, Mohamed SMB, Thomas M, Kuruvilla L, Sumesh KV, Annamalainathan K. 2015. Quantitative expression analysis of drought-responsive genes in clones of Hevea with varying levels of drought tolerance. Physiol Mol Biol Plants 21 (2): 179-186. DOI: 10.1007/s12298-015-0288-0

Mishra KB, Mishra A, Novotná K, Rapantová B, Hodaňová P, Urban O, Klem K. 2016. Chlorophyll- $a$ fluorescence, under half of the adaptive growth-irradiance, for high-throughput sensing of leaf-water deficit in Arabidopsis thaliana accessions. Plant Methods 12 (46): 1-17. DOI: 10.1186/s13007-016-0145-3

Murchie EH, Lawson T. 2013. Chlorophyll fluorescence analysis: a guide to good practice and understanding some new applications. J Exp Bot 64 (13): 3983-3998. DOI: $10.1093 / j x b / e r t 208$

Ögren E, Sjöström M. 1990. Estimation of the effect of photoinhibition on the carbon gain in leaves of a willow canopy. Planta 181: 560-557.

Sanier C, Oliver G, Clément-Vidal A, Fabre D, Lardet L, Montoro P. 2013. Influence of Water Deficit on the Physiological and Biochemical Parameters of in vitro Plants from Hevea brasiliensis Clone PB 260. J Rubber Res 16 (1): 61-74.

SAS Institute Inc. 2002. The SAS System for Windows. SAS Institute Inc., Cary, NC, USA.

Sasaki H, Li Z, Tsuji K, Oda M. 1994. Factors Affecting the Measurement of Chlorophyll- $a$ Fluorescence in Cucumber Leaves. Jpn Agric Res Q 28 (4): 242-246

Stirbet A, Govindjee. 2011. On the relation between the Kautsky effect (chlorophyll- $a$ fluorescence induction) and Photosystem II: Basics and applications of the OJIP fluorescence transient. J Photochem Photobiol B 104 (1-2): 236-257. DOI: 10.1016/j.jphotobiol.2010.12.010

Stirbet A, Lazár D, Kromdijk J, Govindjee. 2018. Chlorophyll- $a$ fluorescence induction: Can just a one-second measurement be used to quantify abiotic stress responses? Photosynthetica 56 (1): 86-104. DOI: $10.1007 / \mathrm{s} 11099-018-0770-3$

Thomas M, Xavier SM, Sumesh KV, Annamalainathan K, Nair DB, Mercy MA. 2015. Identification of Potential Drought Tolerant Hevea Germplasm Accessions using Physiological and Biochemical Parameters. Rubber Sci 28 (1): 62-69.

Tsai Y-C, Chen K-C, Cheng T-S, Lee C, Lin S-H, Tung C-W. 2019. Chlorophyll fluorescence analysis in diverse rice varieties reveals the positive correlation between the seedlings salt tolerance and photosynthetic efficiency. BMC Plant Biol. 19 (403): 1-17. DOI: 10.1186/s12870-019-1983-8

Ulqodry TZ, Matsumoto F, Okimoto Y, Nose A, Zheng S-H. 2014. Study on photosynthetic responses and chlorophyll fluorescence in Rhizophora mucronata seedlings under shade regimes. Acta Physiol Plant 36: 1903-1917. DOI: 10.1007/s11738-014-1566-0

Zushi K, Matsuzoe N. 2017. Using chlorophyll- $a$ fluorescence OJIP transients for sensing salt stress in the leaves and fruits of tomato. Sci Hortic 219: 216-221. DOI: 10.1016/j.scienta.2017.03.016 